\title{
LA GUERRA CIVIL EN TOLEDO (1936-1939). UNA PROPUESTA METODOLÓGICA PARA SU ESTUDIO DESDE LA ARQUEOLOGÍA
}

\author{
J. Morín, R. Barroso, J. Carrobles, A. Malalana, J. Ramos, J.L. Isabel. L. \\ Rodríguez-Avelló y L.A. Ruiz Casero ${ }^{1}$
}

\section{Resumen:}

En el presente estudio se aborda la problemática de la arqueología de la Guerra Civil en Toledo. La ingente bibliografía histórica se ha centrado prácticamente en exclusiva en el estudio del episodio del Alcázar, olvidando la constitución de un frente al Sur del río Tajo, uno de los más importantes de la contienda española. Los trabajos de prospección se han centrado en la documentación exhaustiva de este Frente Sur del Tajo como una sola unidad, incluyendo todos los sistemas de fortificación. Por otro lado, el estudio de la cultura material recogida permite asignar las posiciones a uno y otro bando, ya que no se trató de un frente estable, sino que se vivieron diferentes episodios de cambios de posiciones entre el inicio y el final de la contienda.

\section{Palabras clave:}

Guerra civil, Toledo, Frente Sur del Tajo, arqueología, methodology.

\begin{abstract}
:
This study tackles with the problems associated with the Spanish' Civil War archaeology in Toledo. Nearly all the historical bibliography related to it has been based in the Alcazar episode, leaving aside the existence of the river Tajo's South Front, one of the most important in this conflict. The survey works have been based in an exhaustive documentation of this front, considering it as a sole unit, including all the fortified systems. On the other hand, by the study of the material culture recovered, it is possible to assign the positions to one side or the other; it wasn't a stable front, as there were several position change episodes during the war.
\end{abstract}

\section{Key words:}

Spanish Civil War, Toledo, Tajo’s South Front, archaeology, methodology.

1 Departamento de Arqueología de AUDEMA. Calle Felipe Campos, 3. 28002 - Madrid; www. audema.com; jmorin@audema.com. 
En el año 2009 iniciamos el proyecto de investigación "Paisajes culturales en la ciudad de Toledo: los cigarrales" ${ }^{2}$. Desde entonces se han realizado diferentes actuaciones arqueológicas que buscaban la definición de los diferentes paisajes culturales de Toledo. Uno de los paisajes con el que nos hemos encontrado una y otra vez, tiene un carácter efímero, pero ha adquirido una importancia insospechada por la falta de referencias históricas previas con las que partíamos en nuestra investigación. Nos referimos al hallazgo de las evidencias relacionadas con la constitución de un frente de guerra en la zona de los cigarrales que se mantuvo activo durante los tres años que duró la guerra civil. La huella dejada por los combates, los cambios de posiciones y la importancia que las destrucciones ocasionadas tuvieron en la posterior evolución de estas fincas, han hecho que dediquemos un cuidado especial en conocer los hechos ocurridos en los alrededores de la ciudad de Toledo durante los años que duró el enfrentamiento. Su estudio permite conocer la peculiar organización del espacio objeto de estudio, en un momento en el que todavía podemos reconocer algunos de los restos materiales inmuebles y muebles de los restos materiales relacionados con estos acontecimientos ${ }^{3}$. Por último, también se ha realizado un estudio histórico y documental exhaustivo, del que ya se han adelantado algunas publicaciones referentes a los episodios del año 1937 a cargo de L.A. Ruiz Casero ${ }^{4}$.

\section{El contexto histórico}

Las monografías que se dedican a la Guerra Civil española recogen con profusión el episodio del Alcázar, desde esa fecha rara vez se menciona ninguna actividad bélica en los alrededores de la ciudad de Toledo, lo mismo ocurre con los trabajos específicos sobre la guerra civil en la zona. Sin embargo, un estudio arqueológico y documental exhaustivo nos muestra una realidad bastante más compleja que tiene como principal consecuencia la construcción de un paisaje bélico con diferentes momentos. Esta circunstancia es inusual en los acontecimientos bélicos de la Guerra Civil española, ya que se suceden numerosos episodios que se

2 Los trabajos se han recogido en una monografía editada en los BAR: Carrobles, J. y Morín, J -eds., Los paisajes culturales de la ciudad de Toledo. Dehesas, espacios irrigados, torres, cigarrales y trincheras. BAR Internacional Series 2638. Oxford, 2014.

3 Este aspecto ha sido abordado en diferentes publicaciones como Barroso Cabrera R. et al. "Arqueología de la Guerra Civil en Toledo. El Frente Sur del Tajo y el Cigarral de Menores: un escenario de guerra", Archivo Secreto. Revista Cultural de Toledo, 5, 2011, pp. 330-348 y La Guerra Civil en Toledo: El Frente Sur del Tajo. Metodología para el estudio de un frente de la guerra civil española, en VII Jornadas del Patrimonio Arqueológico de la Comunidad de Madrid (Madrid, 2010. Madrid, 2014, pp. 327-399.

4 El tema ha sido objeto de una Memoria de Licenciatura por parte de L.A. Ruiz Casero, que ha sido editada en la Colección Toledo: Paisajes. Textos universitarios: Los combates al Sur del Tajo: Un enfoque patrimonial de un escenario de la Guerra Civil. Madrid, 2014. El autor cuenta con una obra de carácter divulgativo que sintetiza y analiza los acontecimientos históricos, en especial los del año 1937: Más allá del Alcázar. La batalla del sur del Tajo. Toledo y Argés. Madrid, 2015. 
desarrollan en escenarios geográficos diferenciados. Sirva de ejemplo uno de los ejemplos mejor conocido como la Batalla de Madrid, que genera la construcción de un dispositivo alrededor de la ciudad, con posterioridad el frente se traslada al Jarama y el último momento se vive en tierras de la provincia de Guadalajara. En Toledo, asistimos a la construcción de un frente espontáneo en los meses posteriores al episodio del Alcázar; la generación de un frente en movimiento en 1937, con cruentos combates en el Cerro de los Palos y La Sisla; la constitución de un frente estable en 1938 y, por último, la ciudad es protagonista de la ofensiva final para finalizar la contienda. Un paisaje bélico, pero no homogéneo, sino superpuesto, con la complejidad que supone su estudio. En este sentido, su estudio es una novedad arqueológica, ya que se aborda de forma unitaria todo el frente. Para ello se ha elaborado un GIS que recoge la información de campo, así como importantes novedades documentales, tanto de la fotografía aérea, como de planimetrías de ambos bandos, en su mayor parte inédita. Por último, destacar que para una correcta adscripción cronocultural de cada fortificación se ha realizado un estudio minucioso de la cultura material asociada, lo que permite su datación y adscripción militar sin ninguna duda.

Tal y como decíamos, el asedio y la liberación del Alcázar y en todo caso la campaña a través del Tajo que permitió la conquista de la ciudad por parte del Ejército Nacional, han centrado la atención de la mayoría de los estudios sobre la Guerra Civil en Toledo, dada la evidente repercusión mediática y propagandística que tuvo este suceso durante la contienda y en la inmediata posguerra. No obstante y de acuerdo con lo que hemos avanzado anteriormente, la población se mantuvo como un punto sensible durante los más de dos años que aún duró la guerra. En efecto, después de la caída de la ciudad en manos del General Varela, Toledo se integró en uno de los frentes de guerra -el denominado Frente Sur del Tajo (FST) por el Estado Mayor republicano- y desempeñó un cierto papel estratégico al utilizarse de plataforma para la organización de diferentes intentos de ruptura.

El frente, tal y como se configuró a lo largo de 1937, seguía la línea del Tajo que unía la localidad de Puente del Arzobispo con la de Aranjuez y se convirtió en un sector estratégico sensible por diferentes motivos. Para el Ejército Nacional porque ofrecía la posibilidad de avanzar sobre el sudeste aprovechando los puentes del Tajo y podía contribuir, de esa manera, al dispositivo trazado para la conquista de Madrid, mediante la apertura de posibles vías de ataque o la realización de operaciones con las que lograr el desvío de tropas cualificadas de la capital. Para los republicanos porque abría la posibilidad de partir en dos el territorio controlado por los nacionales en torno a Extremadura con el que favorecer un levantamiento popular en Andalucía, por mantener la posibilidad de aspirar a la conquista de Toledo con las repercusiones mediáticas que ese hecho pudiera tener en la prensa internacional y, sobre todo, porque también constituía 
un punto de referencia auxiliar para la Batalla de Madrid, al permitir una posible línea de avance sobre la retaguardia de las tropas nacionales que atacaban la capital desde el Oeste. De hecho y al poco de la conquista de Toledo por las tropas de Varela, la zona del valle del Tajo en la que se encuentra la ciudad había sido objeto de un fallido intento de contraataque republicano iniciado en los sectores de Seseña, Illescas y Torrejón de Velasco.

A partir de este momento el FST empezó a configurarse y quedó como un frente activo pero secundario, al estar presente en los planes de ambos ejércitos hasta el final de la contienda en que alcanzó un último y destacado protagonismo poco conocido, al que dedicamos la parte final de este trabajo. Este nivel de actividad del que hablamos se puso de manifiesto en toda una serie de operaciones de bombardeo artillero, de golpes de mano y, sobre todo, de intensas aunque cortas batallas libradas en las inmediaciones de Toledo, que destacan por su dureza, los escasos resultados obtenidos y, como consecuencia de todo ello, por el olvido que ha caído sobre ellas. La más importante de todas fue la que tuvo como fin la ampliación de la cabeza de puente entre los sectores del puente de Alcántara y el de San Martín, Ilevada a cabo por las tropas nacionales entre los días 7 y 13 de mayo de 1937. Esta operación, conocida como el "combate del cerro de los Palos" y en algunos medios como "batalla de los cigarrales", fue diseñada por el entonces coronel Yagüe que venía protagonizando algunos de los avances más destacados realizados por el Ejército Nacional hasta entonces. En principio el plan fue concebido como una acción puntual, circunscrita a un ataque para la ampliación de la cabeza de puente de San Martín con objeto de conquistar las alturas que dominan Toledo en la margen opuesta del Tajo, desde las que se controlaba la ciudad y la Fábrica de Armas, que se había convertido en un importante objetivo para los contendientes. Sin embargo, esta acción limitada en sus fines e incluso recortada en efectivos y alcance por el General Saliquet antes de ejecutarse, se convirtió en un enfrentamiento cruento en el que ambos contendientes se vieron obligados a recurrir a sus mejores armas y unidades. El ataque inicial del Ejército Nacional cogió completamente desprevenidas a las tropas republicanas de los coroneles Uribarri y Ropero que habían fijado sus posiciones en diferentes cigarrales, descuidando la creación de un auténtico frente militar que, en caso de haber existido, hubiera obstaculizado el avance que no tuvo dificultad para adentrarse en las líneas atacadas y Ilegar hasta poblaciones como Argés que no figuraban en el plan inicial.

La maniobra como decimos sorprendió al ejército pero también a las autoridades republicanas, que creyeron encontrarse ante un intento de ruptura del todavía naciente frente en toda regla. Para evitar las consecuencias que este ataque podía ocasionar y no renunciar al objetivo toledano que tanto valor mediático ofrecía, el Ejército Republicano ordenó el despliegue de las tropas más experimentadas de las que disponía, agrupadas en la $11^{\text {a }}$ División dirigida por Enrique Líster, 
que permitió, muy a duras penas y con un elevado coste de material y hombres, contener el avance y conquistar algunas de las posiciones en las que el Ejército Nacional había iniciado obras de fortificación. El resultado final fue de cierta ventaja para las tropas nacionales que consiguieron la ampliación de la cabeza de puente de San Martín y mantener las principales posiciones ganadas al inicio de la ofensiva. Más dudas ofrece la valoración del objetivo relacionado con el alejamiento de los observadores republicanos que controlaban visualmente la Fábrica de Armas y dirigían los ataques de la artillería, al permanecer en su poder una serie de posiciones fortificadas en la zona de los cerros del Valle y la Sisla, que mantuvieron el control que se quería evitar y que posibilitó nuevos y certeros ataques artilleros en los siguientes meses.

De esta manera y tras cerca de una semana de enfrentamientos constantes en los que se llegaron a producir combates cuerpo a cuerpo y actos de indudable valor en ambos ejércitos, algunos de los cuales fueron reconocidos con la concesión de las condecoraciones más destacadas, finalizó la fase más activa que conoció el Frente y se inició una nueva etapa caracterizada por la fortificación de las posiciones recién adquiridas y la construcción, ahora sí y por ambas partes, de un auténtico frente de guerra que ayudó a estabilizar la situación. Su importancia ha quedado documentada en la entidad de las construcciones realizadas y en el inicio de la ordenación bélica del espacio más cercano al sur de Toledo que, no obstante, todavía iba a sufrir algunas rectificaciones menores a lo largo de 1937 y en menor medida de 1938.

Así, durante ese mismo año de 1937 se produjeron dos nuevos ataques en el FST que ocasionaron escasas modificaciones del status quo. La primera acción, llevada a cabo por parte nacional, fue en realidad un calco de la acción anterior en el entorno del Puente de San Martín, pero esta vez el área afectada fue la del puente de Alcántara. Tuvo lugar el 26 de septiembre y culminó con la rápida conquista de la conocida como "Bolsa de la Sisla" que, como decíamos, seguía ofreciendo un magnífico control visual de las instalaciones militares toledanas que se querían defender. La segunda se produjo en el mes de octubre en una zona más alejada de la ciudad, en la Cuesta de la Reina, al este de Seseña y por iniciativa republicana, que finalizó en un claro fracaso.

De nuevo, en la primavera de 1938 se sucedieron otros golpes de mano e intentos de ruptura por parte de ambos contendientes. El más importante fue el protagonizado por el Ejército Nacional sobre la atalaya de las Nieves, ocurrido el 1 de marzo de 1938, que se saldó con un importante fracaso, lo que motivó un apercibimiento a sus responsables por parte del general Franco, en aras de evitar nuevas acciones semejantes. La respuesta republicana al ataque franquista, llevada a cabo entre los días 26 y 27 de marzo desde las posiciones de Teatina, tuvo un cierto éxito al principio, pero fue rechazada finalmente por la oposición de las tropas legionarias, regulares y requetés, que consiguieron defender con éxito la cabeza de puente de Alcántara. 
Consecuencia de todos estos combates fue que el frente trazado en mayo de 1937 sufrió algunas modificaciones en septiembre de ese mismo año. Desde entonces y a pesar de la continuidad en las operaciones bélicas, las líneas fortificadas quedaron estables y permitieron organizar todo un auténtico paisaje cultural relacionado con la guerra, que tuvo especial protagonismo en un sector algo alejado de la ciudad y del Tajo, al pie de los pequeños montes que separan Toledo de las localidades de Argés, Cobisa, Burguillos y la línea marcada por el Miradero y la Atalaya de las Nieves. Desde allí, el frente cruzaba el río, aguas arriba de Azucaica, ya en la ribera septentrional del Tajo para dirigirse a Seseña por Añover en dirección a Madrid. Su estudio en el área de Toledo lo estamos realizando en estos momentos. Es el caso de diferentes trabajos arqueológicos que hemos avanzado en otras publicaciones (Barroso, et allí, 2011), en los que planteamos una primera reconstrucción del frente y su posterior evolución, al mantenerse activo hasta los últimos días del enfrentamiento.

Todos estos intentos de ruptura ocurridos en Toledo y sus inmediaciones, hay que ponerlos en relación con el resto de las operaciones realizadas en el sector occidental del mismo FST. Es el caso de la realizada por el ejército nacional en los meses de julio y agosto de 1938, que permitió la conquista territorial más extensa en la provincia tras la estabilización de la contienda. Se realizó en dos fases. La primera, tuvo lugar el 19 de julio de 1938 y consistió en un ataque diversivo desde el Puente del Arzobispo que permitió la ocupación de las plazas de Azután y Navalmoralejo. El esfuerzo principal se llevó a cabo unos días después, entre los días 21 y el 23 de agosto, como parte de una operación más amplia que entrañaba el cierre de la bolsa de Mérida. Su éxito permitió la conquista de la comarca de La Jara y el control de la carretera del Puerto de San Vicente-Puente del Arzobispo, ocasionando con ello una clara derrota republicana que alcanzó una gran repercusión en el plano político provincial.

En las próximas líneas expondremos en detalle cada uno de estos enfrentamientos librados a lo largo de tres años por los dos ejércitos, que dejó su huella en el paisaje y cuyo estudio desde perspectivas arqueológicas creemos arroja importantes novedades.

\section{La realidad arqueológica: el frente sur del tajo}

El presente estudio ha realizado una documentación exhaustiva de la totalidad de las posiciones defensivas generadas en la construcción del Frente Sur del Tajo, estudiando todos los elementos como una unidad. La documentación generada se ha traspasado a un Sistema de Información Geográfica para poder abordar el estudio de las estructuras documentadas a diferentes escalas. De acuerdo con las propuestas metodológicas que hemos utilizado y debido a la parquedad de las 
fuentes documentales disponibles, se ha utilizado la cultural material asociada generalmente munición- para asignar las posiciones a cada bando y sus diferentes cambios. Los trabajos de prospección han sido intensivos en la zona de trabajo que hemos definido como área cigarralera. Su ejecución se ha realizado con el apoyo del estudio de la fotografía aérea, tanto actual como de vuelos antiguos, así como de la cartografía histórica. Con posterioridad, se realizó un trabajo de campo más complejo que ha permitido el levantamiento topográfico de cada una de las posiciones documentadas y la recogida sistemática y mapeado de la cultura material asociada.

\section{6: Un frente espontáneo -El Cigarral de Menores y la Quinta de Mirabel}

El lunes 28 de septiembre, la Columna de Barrón se hace con la Fábrica de Armas de Toledo y penetra por la puerta del Cambrón. La ciudad está en manos de las tropas nacionales. A las 10,30 el general Varela llega al Alcázar y es recibido por Moscardó y sus hombres. Varela se desprende de una de sus dos laureadas y se la prende al coronel. Se consuma el mito de la resistencia del Alcázar, aunque la batalla por Toledo, y su posición estratégica, sobre el Tajo no ha finalizado en este día. En los próximos años la ciudad fue testigo de enconados combates de los dos ejércitos por el control de la misma.

Las tropas republicanas han abandonado la ciudad, aunque los que quedan atrapados en el interior de la misma murieron en combate o se suicidan como los tres milicianos del Seminario -Manuel Gómez Cota, Tomás Pargués y Eduardo Ruiz "Meroño"-. Al día siguiente, martes 29, Franco llega al Alcázar y concede la laureada de San Fernando colectiva a los defensores y a título personal, al coronel Moscardó. En estos días las tropas nacionales sólo fueron capaces de asegurar el puente de Alcántara, pero no el de San Martín. Los republicanos después del abandono de la ciudad han ido tomando posiciones en el área cigarralera, desde donde se domina el puente y, más importante, la estratégica Fábrica de Armas, que está a tiro de fusil. Estas posiciones no aparecen recogidas en los partes de guerra o en la prensa diaria. Sin embargo, se puede intuir de la presencia durante unos días de Varela en la ciudad. Éste se ocuparía de asegurar las posiciones, y aunque el objetivo ahora era Madrid, y mejorar su situación que era precaria, ya que podían ser batidos desde las alturas cigarraleras. Por su parte, Enrique Líster recoge en sus Memorias que organizó la salida de las tropas por el Puente de San Martín y estableció dos batallones para cubrir la retaguardia. Arqueológicamente, hemos podido documentar esas posiciones republicanas en el frente que se generó en el área cigarralera, delante del Puente de San Martín.

Es muy probable que entre el 28 de septiembre y el 12 de octubre, las tropas nacionales intentarán mejorar sus posiciones en el puente de San Martín. Con posterioridad a esa fecha se producen los asaltos de Ciudad Universitaria -12 de octubre a 23 de noviembre; carretera de La Coruña -29 de noviembre a 6 de 
enero de 1937-; batalla del Jarama -6 a 27 de febrero de 1937 y Guadalajara -8 a 22 de marzo de 1937-. Más tarde se llevó a cabo en Toledo el asalto al Cerro de los Palos y en ese momento las posiciones del Cigarral de Menores estaban consolidadas. Así, entre el 28 de septiembre y el 12 de octubre, las tropas de Varela se lanzarían al asalto de las posiciones republicanas sobre el puente de San Martín, alcanzando el Cigarral de Menores. Su línea quedaría establecida en las cotas al Norte de la casa, mientras que los republicanos se parapetarían tras las cercas del Cigarral de Menores y la Quinta de Mirabel en la carretera a Argés. El cigarral, en una vaguada, quedaría en tierra de nadie.

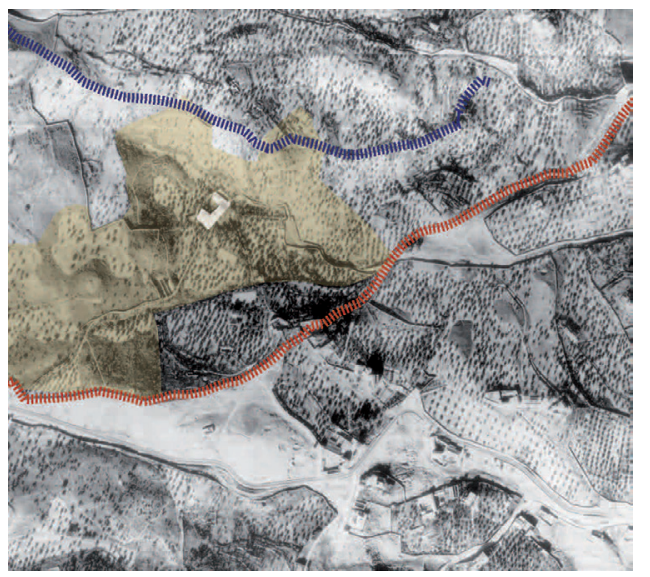

Fig. 1. Fotografía aérea con la línea de frente que se forma después del episodio del Alcázar. Arriba las posiciones nacionales. Abajo las posiciones republicanas y entre los dos frentes el Cigarral de Menores.

Las posiciones republicanas serían batidas por fuego artillero desde San Juan de los Reyes, donde se estableció una pieza de artillería de gran calibre, y tomadas al asalto con combates cuerpo a cuerpo, como se atestigua en las excavaciones realizadas en las posiciones del Cigarral de Menores, donde se ven los impactos de la fusilería, el empleo de armas cortas y las granadas. El origen de la munición, tanto la nacional como la republicana, que no rebasan la fecha de 1936, no está datando el momento del conflicto. De hecho, en los combates del cerro de los Palos de 1937 ya es mayoritario el uso de munición soviética en las tropas republicanas, que aquí no se recoge.

La situación de las tropas nacionales en la ciudad no mejoró mucho tras estos golpes de mano, ya que los republicanos tenían a tiro la ciudad y la Fábrica de Armas. La arqueología resulta crucial para identificar estas primeras posiciones y establecimiento de un frente provisional, ya que éste no aparece recogido en las fuentes históricas al tratarse de un frente secundario, no prioritario como el de Madrid en los meses del otoño del 36. En el Cigarral de Menores se prospectaron 
las posiciones de ambos bandos, geo-referenciando los objetos materiales, que en su mayoría se trataba de munición ${ }^{5}$.

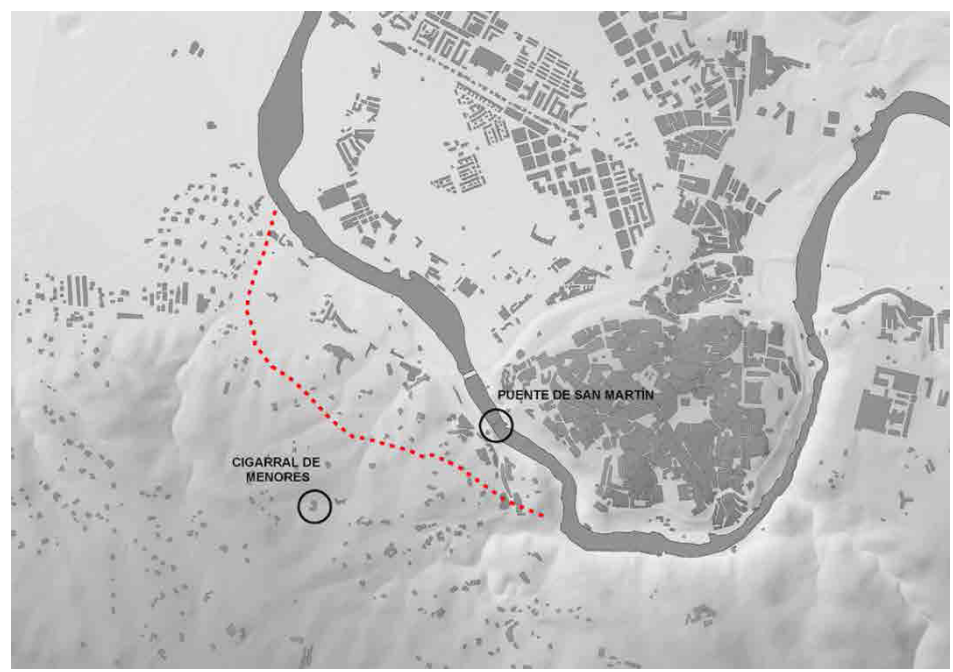

Fig. 2. Frente en Septiembre de 1936.

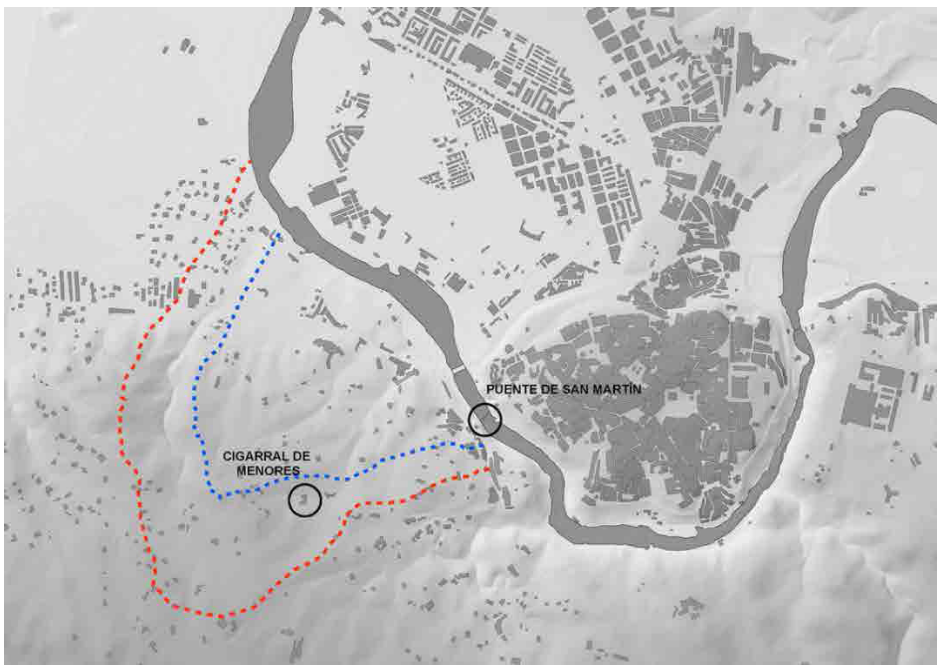

Fig. 3. Frente en Octubre de 1936.

La lectura de esos marcajes permite la atribución de las posiciones a un ejército u otro, así como el año/meses de su ocupación. Finalmente, señalar que se excavó una de las posiciones nacionales.

5 Los trabajos arqueológicos realizados en el Cigarral de Menores están recogidos en J. Carrobles y J. Morín -eds.-: Torres, cigarrales y trincheras.El Cigarral de Menores. Toledo, 2015. 


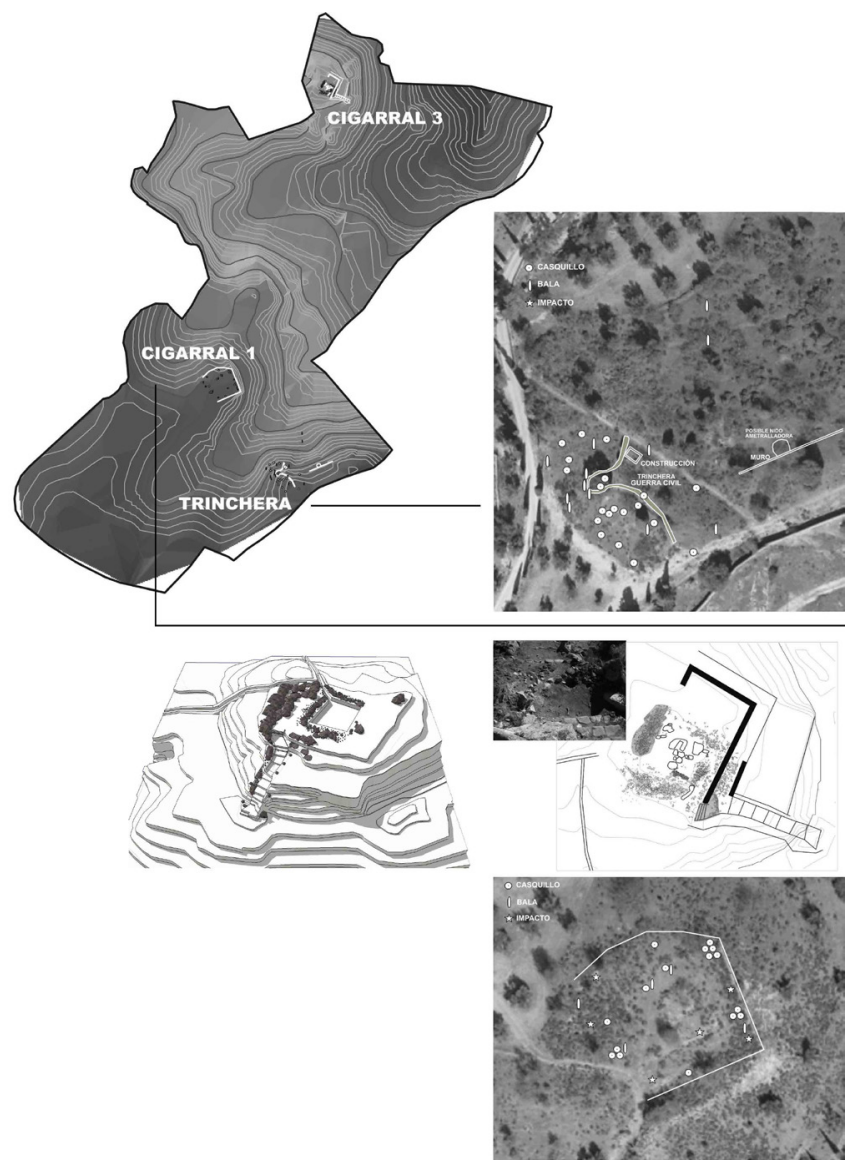

Fig. 4a-d. Posiciones en el Cigarral de Menores. A. Plano general; B. Posición republicana; C. Posición nacional y D-E. Excavación puesto nacional.

\section{7: Frentes en Movimiento -Cerro de los Palos y La Sisla}

El ataque nacional del 7 de Mayo de 1937, que se prolongó hasta el día 13, supuso la construcción de un nuevo frente, mucho más estable y de mayor entidad que el que se había desarrollado anteriormente. Las tropas nacionales ocupaban sus posiciones en el Cerro de los Palos aunque no lograron su objetivo de unir las dos cabezas de puente de Alcántara y San Martín. Por el contrario, las tropas republicanas se fortificaban alrededor del Palacio de la Sisla y la Casa de la Legua.

Este nuevo frente conllevó la construcción de trincheras y blocaos por ambos bandos separados entre si por escasos metros, creando un frente discontinuo que prácticamente se mantuvo estable hasta el año 1938.

Los trabajos de prospección han estado encaminados a la documentación exhaustiva de este frente, poco conocido y de difícil reconocimiento a través 
de la documentación histórica. Se han identificado las estructuras defensivas y se han recogido los materiales asociados, lo que permite adscribir a uno u otro bando las posiciones.

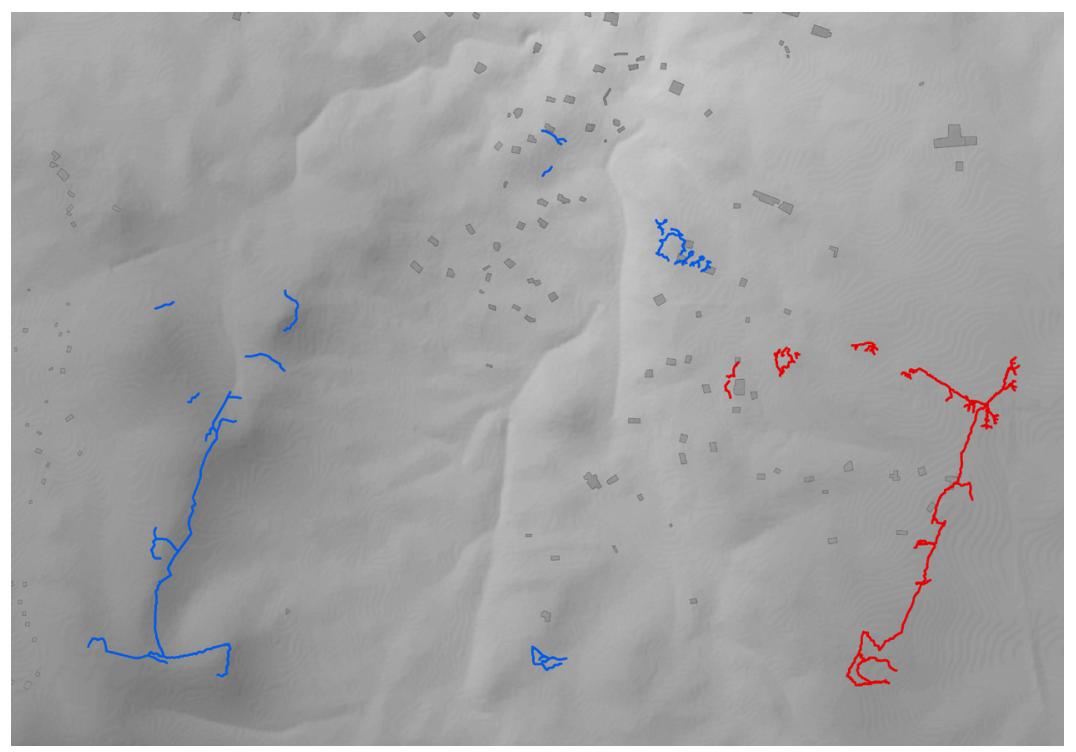

Fig. 5. Frente después de Mayo de 1937.

\section{Cerro de los Palos. Líneas Nacionales}

Este ámbito escogido, denominado en el estudio "sector Cerro de los Palos", comprende un espacio definido por un rectángulo de 1,5×3,5 km, el cual incluye las líneas de trincheras y posiciones establecidas a lo largo del cerro de las Lomas hasta el límite del municipio de Toledo con Argés. Este cerro es en realidad una pequeña y suave ondulación en dirección NS que comienza en el propio cerro de los Palos, y llega hasta las primeras urbanizaciones del pueblo de Argés. Esta pequeña elevación tiene cotas ascendentes desde el propio cerro de los Palos (662 m) hasta el cruce del camino que recorre la loma con el camino de las Ballestas, a una cota aproximada de $697 \mathrm{~m}$, donde finaliza la zona de prospección. Las pendientes asociadas a esta elevación varían según la orientación; en líneas generales, estas pendientes son ligeramente más elevadas en las laderas orientales, donde se sitúan la mayor parte de las trincheras prospectadas, que en las occidentales

Como ya se ha comentado, las trincheras estudiadas son aquellas situadas en el sector denominado "Cerro de los Palos", que ocuparía la zona comprendida entre el vértice Pozuela y el cruce del camino de las Lomas con el camino de las Ballestas. Fueron numeradas desde dicho cerro hasta el final de la zona de prospección, localizándose finalmente en campo las siguientes: 

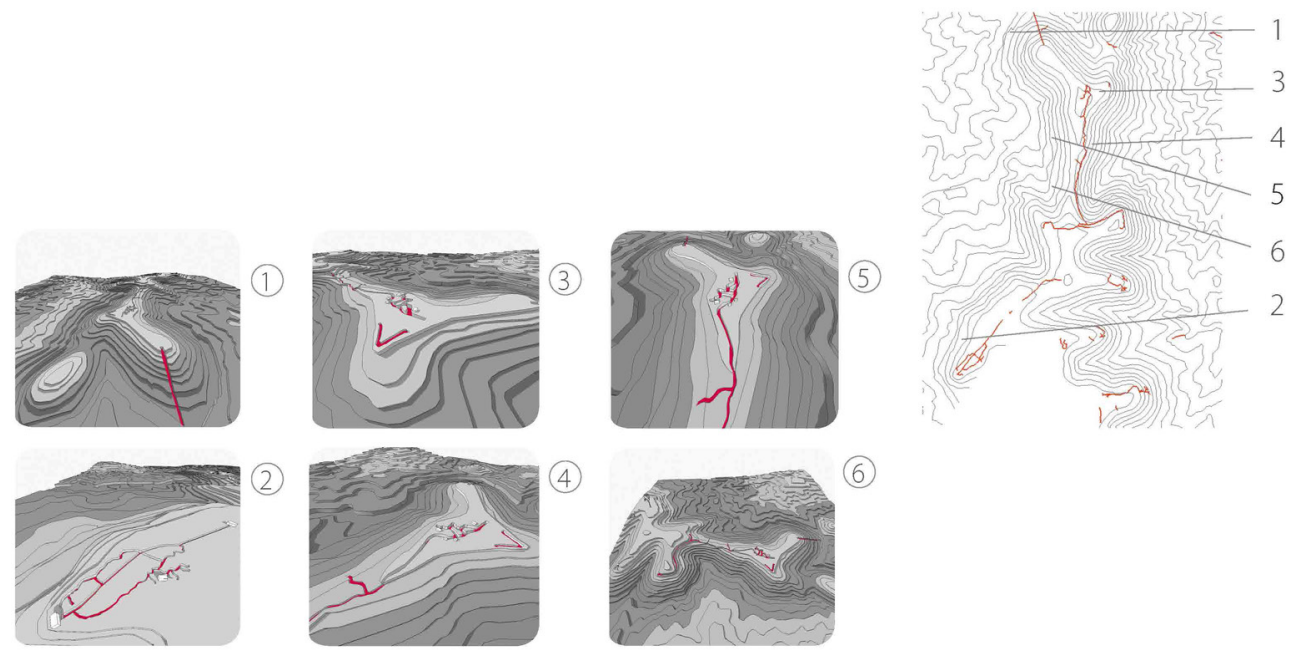

Fig. 6. Posiciones nacionales en el Cerro de los Palos.

\section{TRINCHERA 2}

Situada en la ladera Norte del vértice Pozuela, que recorre en sentido NS, a lo largo de 200 m aproximadamente, en línea recta. Tiene una profundidad de 30$50 \mathrm{~cm}$ en su parte menos colmatada. Presenta una pequeña cavidad en la zona donde se une a la trinchera 3, que pudiera ser un puesto de tirador. Se interrumpe en el corte con el camino que recorre este cerro por su base.

Lo más probable es que se trate de una trinchera de desplazamiento hasta el propio vértice Pozuela, lugar donde según los planos elaborados la Sezione Topocartografica del CTV italiano se ubicaba un observatorio, se intuye que artillero, para las baterías de la unidad Santa Bárbara. Esta unidad contaba con 3 baterías de $105 \mathrm{~mm}$ y una de $152 \mathrm{~mm}$. En la actualidad no se han documentado restos del probable puesto de observación en dicho vértice, quizás destruido tras las obras de construcción de las infraestructuras presentes actualmente. En las siguientes figuras y fotos acompañantes puede observarse tanto la ubicación de esta trinchera como su aspecto actual:

\section{TRINCHERA 3}

Parte de la zona media de la trinchera 2, contando ésta con cierta forma de "s", de la cuál la anterior carecía. Bien perfilada, con la pared Norte visiblemente más gruesa que la Sur, lo cuál indica que es esta orientación la que cubre dicha trinchera. Más profunda que la anterior, al menos $50 \mathrm{~cm}$. Recorre aproximadamente $43 \mathrm{~m}$ de ladera. Tiene también un pequeño socavamiento en su zona media, en 
la pared posterior, por lo que no es un puesto de tirador; quizás zona de refugio/ almacén.

\section{TRINCHERAS 6 Y 7}

Estas trincheras se engloban dentro de la posición $n^{0} 7$, epígrafe bajo el cual se engloban todas las trincheras del bando nacional presentes en el sector que hemos definido como "cerro de los Palos". En concreto, la que denominamos como 6 y 7 son en realidad una trinchera de desplazamiento que siguiendo la curva de nivel llega hasta una serie de estructuras, derruidas en su mayor parte, en el cerro vecino al vértice Pozuela por el Este. Esta trinchera de desplazamiento recorre 700 metros aproximadamente, tiene al menos tres desvíos hacia la ladera Oeste, posibles puestos de tirador u observación. Al llegar al depósito situado en el camino de la Raya la trinchera se bifurca hacia dos posiciones, cada una cubriendo una ladera del cerro de las Lomas. El estado de conservación de este sistema de trincheras es aceptable, aunque en muchos puntos están muy colmatadas, sin duda por efecto de la mayor pendiente que se da en estas laderas. Las estructuras localizadas en el extremo Norte de la trinchera de desplazamiento presentan un grado de deterioro dispar: dos de ellas, situadas en la zona superior de la loma, se encuentran derruidas; hay otra estructura algo mejor conservada, de estructura semicircular, que según algunas informaciones pudo ser un palomar empleado para guardar las palomas mensajeras. Bajando por la ladera norte, a escasos metros de los restos de los búnkeres aparecen las entradas a un refugio subterráneo contra artillería; está formado por dos estancias, en una de las cuales aún puede verse en forma de graffiti en la pared la unidad que lo construyó "41 COMPAÑÍA ESPECIAL DE ZAPADORES", así como varios símbolos franquistas. Según los planos del CTV en esta zona se ubicaba el observatorio de la artillería adscrita a la unidad Vittorio Veneto, que contaba con 3 grupos de artillería de $149 \mathrm{~mm}$.

Con respecto a la trinchera 6 , se trata de una pequeña trinchera en forma de media luna con una pequeña excavación en uno de sus extremos. Por su pequeño tamaño y cercanía al refugio, pudiera tratarse de un puesto de escucha u observación avanzado.

Tanto por su ubicación como por su fisonomía, parece que este conjunto de trincheras así como las posiciones a las que se asocian, a lo largo de los entrantes del cerro de las Lomas sobre el valle de la Pozuela, cubrían el sector frente a las trincheras republicanas, presentes en un primer momento, en la ladera opuesta de dicho valle. Contribuyendo a esta función hay otras estructuras, integradas dentro de la misma línea de defensa: un búnker situado en el cerro de la Mira y un puesto de observación/escucha.

En cuanto a los materiales encontrados, sobresale la gran cantidad de proyectiles encontrados, muchas de ellas impactadas, así como la cola de un mortero Brandt 
y un peine con dos cartuchos sin percutir, encontradas en la ladera que sube desde la trinchera 6 a los búnkeres de la zona superior del cerro.

\section{TRINCHERA 9}

Trinchera que rodea el cerro denominado Laderón o Narizone, por sus caras Norte y Este, de manera que contribuye a cubrir el pequeño valle asociado al arroyo de la Pozuela, cubierto en parte también por la trinchera 7. Recorre en total aproximadamente 330 metros, y presenta varios desvíos de la trinchera principal que conducen a puestos de tirador, parcialmente rellenos por material, en la parte de la trinchera que mira al Norte. Su estado de conservación es malo, se encuentra bastante rellena de sedimento, sobretodo el flanco Norte; la zona Este se conserva en mejor estado. Es en esta zona donde se detecta una mayor complejidad, con varias zonas amplias fuera de la trinchera principal, y un socavón que pudiera ser un refugio/almacén de material, al final de la trinchera.

En cuanto a los materiales encontrados en esta trinchera, destaca sobretodo un cartucho mexicano, aparecido en la pared de la trinchera que cubre el flanco Este., pared que parece engrosada con respecto a las que cubren el flanco Norte. Al aparecer en esta ubicación es presumible que esta trinchera fuera abandonada por tropas republicanas, ya que fueron las únicas que contaron con munición de esta procedencia, y al ocuparla las nacionales la reconstruyeron, de ahí que salga este cartucho (entro otros materiales) aquí. Esta dinámica se repite en las paredes que cubren el flanco Este de varias de las posiciones prospectadas.

\section{TRINCHERA 10}

Pequeña trinchera que discurre desde la confluencia con las trincheras 7 y 9, a escasos metros del depósito situado en el camino de las Raya. Se trata de una trinchera en un primer momento lineal, que luego describe un semicírculo hasta el campo de cultivo; en la foto aérea parece que pudiera seguir en línea recta, sin que se haya detectado en campo evidencias de esto. Su longitud es de aproximadamente 230 metros, sin que se hayan podido identificar otras estructuras diferentes a la propia trinchera. Se conserva en buen estado la parte lineal, no así la zona semicircular, bastante desdibujada. Resaltar la presencia de escombros en mayor proporción que en las trincheras descritas hasta ahora, por la presencia cercana de viviendas. Esta trinchera, de acuerdo con los planos elaborados por la Comandancia General de Artillería del Ejército de Centro, tendría su continuación a través de los campos de cultivo aquí presentes con la que llega hasta la trinchera 17 , en la que muestra una gran profundidad y anchura., constituyendo un buen ejemplo de trinchera de transporte, para permitir tanto el desplazamiento de tropas de una forma rápida por la posición del Cerro de los Palos (posición $n^{\circ} 7$ ) como vehículos. 


\section{TRINCHERAS 12 y 13}

El conjunto de trincheras 12 y 13 se sitúa en uno de los entrantes que desde el camino de la raya miran hacia el valle de la Pozuela, al igual que la trinchera 9, 14, 15 y 21. Todas ellas presentan la misma tipología: una trinchera de desplazamiento que se desgaja en varios puestos de tirador, que a veces acompañan a emplazamientos de armas automáticas. Normalmente cuentan con una o dos oquedades, posibles refugios o almacenes. La trinchera 12 en particular presenta una configuración con un ramal principal que en su extremo se subdivide, quedando varios puestos de tirador y un nido de ametralladora, tal y como se indica en los manuales al uso.

La trinchera 12 ocupa una longitud aproximada de 140 m desde el comienzo hasta los pozos de tirador. Esta trinchera se encuentra razonablemente bien conservada, sin estar demasiado colmatada. A mitad de trinchera aparece una zona más ancha, que pudiera constituir un abrigo/refugio. En la zona final se sitúa el nido de ametralladora, de pequeñas dimensiones (sólo cabe un arma automática). Se encuentra colmatado de tierra de manera que no se puede acceder a su interior. En la parte frontal tiene una inscripción, ilegible. En la trinchera 13 también se han localizado los restos, más deteriorados, de otra estructura de hormigón, aunque por la tipología de los restos y que esté excavado en el terreno pudiera haber constituido un refugio. Es presumible que ambas trincheras hubiesen estado conectadas por otra de desplazamiento. A los lados de ambas estructuras se ubican los pozos de tirador, controlándose desde todo el conjunto otra parte del sector del valle del arroyo de la Pozuela, complementándose esta posición con las de las trincheras 9, 14, y15.

\section{TRINCHERAS 14 Y 15}

Al igual que la posición anterior, estas trincheras se ubican en el entrante sobre el valle de la Pozuela, proporcionando una defensa de la posición 7 muy adecuada, con un gran campo de visión. Hay una trinchera de desplazamiento en forma cuadrangular que recorre las 3 caras del entrante. Trinchera de la cual salen varias ramificaciones con los correspondientes pozos de tirador, parte de los cuales acompañan dos nidos de ametralladora. Asimismo, se documentó un refugio subterráneo, o más bien los restos. Todas estas estructuras se complementan con otros dos nidos de ametralladora situados en el propio camino de la Raya., ya que el frente estabilizado hasta el final de la guerra se situaba a partir de estas trincheras hacia el Sur. El estado de la trinchera es peor que la anterior, bastante desdibujada sobretodo en la ladera Sur; la trinchera de la ladera Norte está mejor conservada, siendo más profunda. Con respecto a las estructuras identificadas, uno de los nidos conserva el techado pero está inaccesible, y el otro ha perdido el techado. A destacar la tipología de uno de ellos, distinta de las vistas hasta ahora: presenta una forma trapezoidal, con 3 bocas de fuego en vez de una sola 
como son los documentados hasta el momento. Este es el que se encuentra en mejor estado, conservando el techado y la estructura, aunque por la colmatación con tierras no puede accederse a él. Los situados en el camino de la Raya están derruidos, posiblemente dinamitados tras la guerra civil. Todas estas estructuras cubren el camino de la Raya, la vaguada entre este cerro y el situado al Sur y la ladera que vierte hacia el valle del arroyo de la Pozuela.

Además de los emplazamientos de armas automáticas, en las trincheras se han documentado los restos de al menos dos estructuras de hormigón adicionales: una de ellas se trata de un refugio subterráneo, al estar excavado en el terreno y conservar aún la entrada. De la otra estructura sólo se conservan lo que parecen cimientos, sin que se pueda identificar más allá.

\section{TRINCHERA 17}

La clasificada como trinchera 17 es un conjunto que engloba una posición que cubre el flanco Oeste del cerro de Las Lomas, una gran trinchera de desplazamiento de vehículos y material que llega hasta el camino de la Raya y varias estructuras en dicho camino. Esta trinchera llega hasta el final de la posición, desembocando en uno de los nidos de ametralladora flanqueado por varios pozos de tirador. El otro nido de ametralladora cubre el flanco Sur, mostrando una configuración también flanqueado por varios pozos de tirador, y una oquedad (refugio o almacén) en su parte posterior, en la zona interior de la posición. Ambos nidos de ametralladora, asociados a los localizados a 240 metros por el camino de la Raya, en dirección Sur, se complementan a su vez con el descrito en las trincheras 14 y 15 . Se encuentran destruidos. Mencionar también la presencia en esta posición o sus cercanías del observatorio para artillería de la división "Frecce Azzurre", dotada con tres grupos de artillería $(65,75$ y $100 \mathrm{~mm}$ ) que se ubicaban en las cercanías.

Esta posición resulta especialmente interesante ya que aparecen una serie de indicios que sugieren la posibilidad de que por aquí se desarrollase un ataque de cierta magnitud: dicha posición muestra una gran cantidad de impactos sobre ella, de artillería o mortero, algunos de ellos directos sobre la trinchera de desplazamiento, especialmente en el flanco Norte y Oeste. Este hecho se corresponde con el hallazgo de abundante metralla en las zonas aledañas a la posición, fragmentos de proyectiles de artillería en su gran parte, además de varias espoletas y fragmentos de ellas, como puede comprobarse en la descripción de los materiales. A esto se añade también la presencia especialmente elevada de cartuchos de Mosin-Nagant, un tipo de munición empleada exclusivamente por el ejército republicano; los cartuchos de este tipo se han encontrado en progresión creciente desde la zona interna de la posición hacia el extremo Noreste, hasta el punto de localizarse una concentración de ellos especialmente elevada en un espacio de aproximadamente $50 \mathrm{~cm}$ de ancho. Esto sugiere el posible emplazamiento de un arma automática traída hasta aquí por el ataque republicano. 
La gran cantidad de material encontrado, su tipología, y el hecho de que en los mapas del Ejército de Centro a todo el conjunto de trincheras del cerro de los Palos se le considere como la posición 7 hace suponer que estos combates fueron los que supusieron la concesión de la "laureada de San Fernando" colectiva a la $7^{\mathrm{a}}$ Bandera de la Legión e individual al entonces alférez Juan José Orozco Massieu, por su defensa. En el escrito de concesión se menciona la conquista parcial de parte de la posición por parte de las tropas de Líster, a pesar de que al final abandonan por la resistencia de los soldados nacionales.
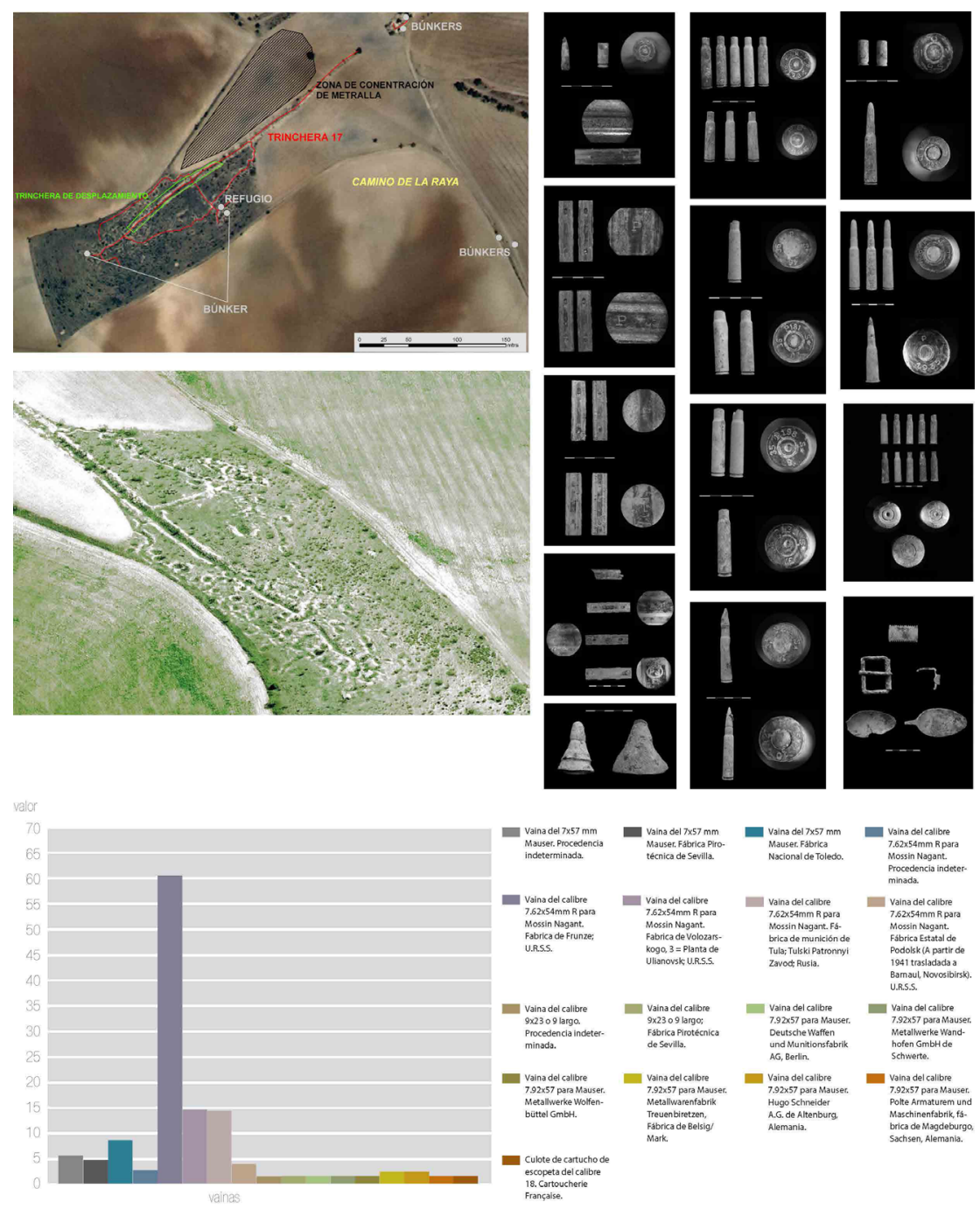

Fig. 7. Planta y fotografía de la posición 7. Materiales recuperados y tabla con la munición recuperada. 


\section{TRINCHERAS 20, 21 y 22}

Estas trincheras constituyen las trincheras de primera línea ocupadas por los republicanos una vez finaliza la batalla del cerro de los Palos y se estabiliza el frente. Forman parte de una posición simétrica a la nacional que se sitúa frente a ellos (esto puede observarse en el mapa de la Comandancia General de Artillería del Ejército de Centro), y que al igual que las nacionales aprovechan una elevación del terreno que penetra ligeramente en el valle de la Pozuela para contar con una posición fortificada elevada, más fácil de defender y con mayor campo de visión del terreno circundante. Se encuadra dentro del sector defendido por la 47 Brigada Mixta, y más concretamente por la $3^{\text {a }}$ Compañía del 187 batallón, perteneciente a la citada Brigada Mixta (según el plano elaborado por el CTV). Fue por aquí donde atravesaron las unidades nacionales en dirección a Argés y Layos en el momento de la rotura del frente, concretamente elementos de la División Frecce Azzurre.

Las posiciones de tiro evidentemente se sitúan mirando al Norte, a las posiciones nacionales, derivándose de una larga trinchera en zig-zag que recorre la curva de nivel del pequeño cerro. En la ladera que mira al Este se sitúan una serie de zonas semiexcavadas en el terreno, conectadas entre sí por trincheras, en lo que podían ser refugios o almacenes, situados en una posición más resguardadas del fuego nacional. Las trincheras se encuentran en bastante mal estado, muy desdibujadas. Destaca, como es natural, la gran cantidad de munición republicana que aparece aquí, principalmente cartuchos de Mosin-Nagant rusos aunque también algún cartucho y peine mexicanos.

\section{TRINCHERAS 23 Y 24}

La trinchera 24 recorre zigzagueante el camino de las Raya hasta el cruce con el camino de las ballestas, límite del municipio de Toledo. Aunque están bien perfiladas y no colmatadas, por situarse en una zona Ilana, su cercanía al pueblo de Argés y el estar al lado del camino hace que hayan sido empleadas como lugar de vertido de basura y escombros. Su longitud es de 440 metros aproximadamente, y presentan al menos 2 trincheras secundarias que llevan a sendos puestos de tirador/observación, en el flanco Este. Estas posiciones estaban defendidas por la $5^{a}$ y $6^{a}$ Compañía del 187 Batallón, perteneciente a la 47 Brigada Mixta.

La trinchera 23 se encuentra en gran parte desaparecida por la ejecución de las obras de la autovía CM-40, inaugurada el 16 de Noviembre de 2010; al ser muy reciente, consta en muy pocas fotografías aéreas por lo que ha sido posible establecer con exactitud las trincheras destruidas.

\section{La Sisla, Casa del Conde y Urbanización Pozuela. La Línea repubicana}

El avance más notorio del bando republicano durante la batalla del cerro de los Palos es el que se produce el 11 de Mayo, una vez se reorganizan las 
unidades presentes en el sector tras la desbandada de los primeros momentos. González Pando, al mando de la Agrupación Derecha, emprende el ataque concentrando sobretodo su artillería en el ataque hacia el palacio de la Sisla, tratando de contrarrestar la superioridad franquista en este sentido. Esta maniobra da el resultado esperado, siendo tomado este enclave por las tropas republicanas al finalizar este día. Presumiblemente, las avanzadillas franquistas presentes en esta zona vuelven a sus posiciones en la zona del arroyo Pozuela, donde deben cubrir el flanco derecho del avance franquista. Tras la conquista de los objetivos, el ejército republicano se presta a la fortificación de las alturas que le permiten dominar, en el caso de las situadas al Norte del palacio de la Sisla, la ciudad de Toledo, y aquellas situadas al Noroeste, las posiciones franquistas en el arroyo Pozuela. Esta será la situación imperante hasta Septiembre de 1937, cuando al parecer tras un bombardeo de la ciudad de Toledo durante una festividad en la que se producen víctimas civiles, se emprenden los preparativos para la ampliación de la cabeza de puente de Alcántara, por la cuál se produce una rectificación del frente que permanecerá estable hasta el final de la guerra.

Los trabajos de prospección de las posiciones clave en este episodio de la batalla del cerro de los Palos han estado condicionados en gran medida por la situación en terrenos privados, como por ejemplo la posición en el cigarral Alto, o por situarse en el campo de maniobras de la Academia de Infantería de Toledo. Es por ello que se ha concentrado el esfuerzo en tres posiciones, las cuales se describen a continuación: Casa del Conde, palacio de la Sisla y Urbanización Pozuela.

POSICIÓN "URBANIZACIÓN POZUELA"

Esta urbanización se encuentra situada en las pequeñas elevaciones al Este del arroyo Pozuela, a medio camino entre el camino de Pozuela y la carretera de Cobisa (TO-7901-V), las alturas no sobrepasan los $600 \mathrm{~m}$. En la actualidad esta zona está ocupada por los chalets de la urbanización, salvo algunas parcelas que aún permanecen sin edificar, como es el caso de aquellas donde se sitúa la posición a describir.

Se trata de una posición en lo alto de una pequeña loma, formada por una trinchera que recorre las laderas a cota de la loma. De esta trinchera se desgajan varios puestos de tirador, poco profundos y conformados por un parapeto en semicírculo, que cubren el flanco Oeste. Asimismo esta posición cuenta con al menos dos estructuras de gran profundidad, aproximadamente 1,8 m, con las paredes talladas en la roca, tratándose probablemente de refugios. Uno de ellos se localiza en la zona de retaguardia, es decir, en la parte trasera de la loma teniendo en cuenta que los puestos cubren el flanco Oeste, y el otro en la ladera Este; éste último se encuentra bien conservado, con un importante parapeto que protegería del fuego procedente de las posiciones del valle de la Pozuela y del cerro de los Palos. 
Durante los trabajos de prospección se documentaron sobretodo vainas de Mauser así como dos peines, todos ellos munición empleada por el bando nacional: son cartuchos de Mauser de fabricación alemana y cartuchos de fusil Carcano, de fabricación italiana. Resaltar la presencia de dos cartuchos Lebel con marcajes americanos (Western); proceden de un contrato del gobierno francés con Estados Unidos, por el cuál éste último fabricó munición para el estado francés, exportándolos éste último a España.

Con respecto a la adscripción de bando de la posición, lo más probable es que fuera una posición avanzada nacional, en relación con los puestos de resistencia a ambos lados del arroyo Pozuela que ocuparon los hombres del Batallón de tiradores de Ifni. No obstante, esto no explica los pozos de tirador y estructuras cubriendo el flanco Oeste; quizás, durante la toma del palacio de la Sisla por los republicanos esta posición avanzada fue abandonada por las tropas nacionales y tomada (o abandonada en tierra de nadie) por el bando contrario.

\section{POSICIÓN “CASA DEL CONDE"}

La posición a describir se encuentra en las cercanías de este lugar, aunque no guarda relación con él; se localiza a unos 400 metros al Norte de dicha casa. Se trata, de nuevo, de otro pequeño cerro fortificado mediante una trinchera en zigzag que recorre la pendiente a cota, con varios puestos de tirador que cubren el flanco Oeste: uno de ellos, el situado más cercano a la alambrada, conserva bien su parapeto y el otro puesto se ubica más hacia el Norte, aprovechando un afloramiento rocoso natural. Tanto por el flanco que cubren, como por el material encontrado en la zona (abundante munición de Mossin-Nagant, en el caso del primer puesto, y cartuchos de ametralladora lebel, en el segundo) hacen suponer sin duda que se trata de una posición republicana. Según la fotografía aérea de la época (1937), esta posición es el extremo de una línea defensiva que protege el palacio de la Sisla, posiciones que mantuvieron hasta septiembre de 1937, cuando el ejército franquista emprende la operación de ampliación de la cabeza de puente del puente de Alcántara.

Esta posición se conecta con el resto que conforman el dispositivo defensivo mediante una trinchera de desplazamiento bastante larga, que aún puede seguirse por el terreno en la actualidad. El estado de conservación es en general bueno, existiendo aún algunos de los parapetos de los puestos así como de la propia trinchera.

\section{POSICIÓN "PALACIO DE LA SISLA"}

Los terrenos de la Academia también incluyen el palacio de la Sisla, que constituyó la conquista más importante por parte de los republicanos tras la desbandada inicial durante las operaciones de ampliación de la cabeza de puente 
de San Martín. Para defender la posición establecieron un sistema defensivo formado por islotes de resistencia en las elevaciones situadas al Norte del palacio, conectadas por una trinchera que a su vez conecta con el propio palacio. La particularidad de estas trincheras es que tras las operaciones de septiembre de 1937, en las que el ejército republicano es obligado a replegarse hacia el Sur, son ocupadas y remodeladas por el ejército franquista de manera que formaran parte de una segunda línea de defensa para cubrir la retirada de las tropas en caso de un ataque republicano. Esto se observa claramente por la disposición de los parapetos y puestos de tirador: los republicanos mirando al Norte y Noroeste, cubriendo posiciones franquistas, y éstos mirando al Sur, frente hasta el final de la guerra.
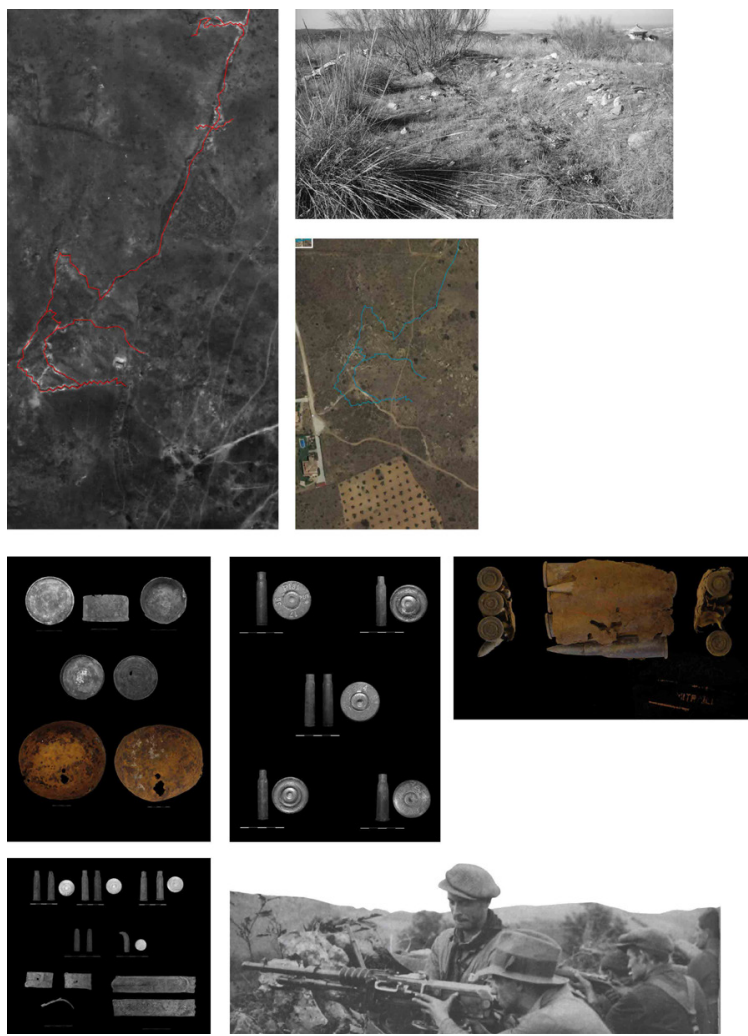

Fig. 8. Planta y fotografía aérea de la posición republicana en Casa del Conde y materiales recuperados.

Las posiciones prospectadas se encuentran bien conservadas, contando con abundantes puestos de tirador franquistas, así como varios espacios que serían refugios de la tropa. Las trincheras republicanas se ubican cubriendo el flanco Norte conservándose varios puestos de tirador con los parapetos en muy buen 
estado, así como al menos un refugio que recuerda a los documentados en la posición Urbanización Pozuela: muy profundos, con las paredes talladas en la roca en los casos en que era necesario, y anchos parapetos de roca. Esta similitud podría indicar que fueron realizados en el mismo período de tiempo, lo cuál limitaría el avance republicano de forma precisa hasta la posición mencionada.

\section{8: Los proyectos de contragolpe republicanos y el Frente Sur del Tajo: un frente estable}

Hasta el final de la guerra el FST siguió en el punto de mira de los Estados Mayores de ambos contendientes. El Estado Mayor republicano, de hecho,

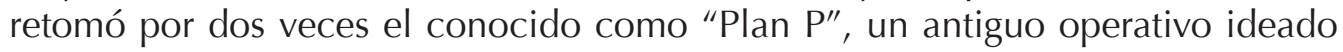
por Vicente Rojo y Largo Caballero en marzo de 1937, que tenía como objetivo dividir en dos zonas incomunicadas el territorio controlado por el bando rebelde. A pesar de que una y otra vez se intentó Ilevar a la práctica, hasta prácticamente

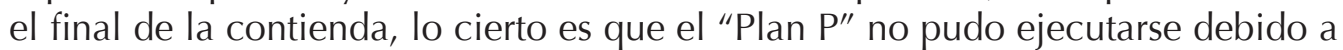
circunstancias diversas, bien políticas o bien de tipo militar. En realidad, el "Plan P" está fechado por primera vez el 22 de abril de 1937, siendo su autor el teniente coronel Álvarez Coque. Este ambicioso plan republicano perseguía un triple objetivo: 1) aislar Andalucía y promover allí un levantamiento campesino en la retaguardia de los sublevados, 2) forzar al enemigo a detraer tropas del Frente del Norte, y 3) obligar al enemigo a retirar tropas del frente de Madrid, aliviando el cerco del ejército franquista sobre la capital, y cortar su línea de abastecimientos. El proyecto estaba avalado por el propio Presidente del Consejo de Ministros, Largo Caballero, pero contaba con la pasiva resistencia del general Miaja, que no quería desprenderse de unidades útiles en la defensa de Madrid en favor de un plan demasiado ambicioso y que fue considerado por muchos analistas como irrealizable. Asimismo, los asesores militares soviéticos, enemistados con Largo y deseosos de su defenestración, veían con malos ojos un plan que, de llevarse a cabo con éxito, no hubiera significado sino el apuntalamiento de la figura de este líder político. Finalmente la operación quedó frustrada al coincidir con la crisis de gobierno alentada por los comunistas que llevó a la destitución de Largo Caballero como presidente del gobierno de la República.

El "Plan P" se retomó por vez primera en noviembre de 1937, ya con Negrín en la presidencia del gobierno. A finales del mes de octubre de ese año todo el Frente Norte había caído en manos del ejército nacional y el Estado Mayor republicano temía que Franco retomase la idea de un ataque sobre Madrid desde Guadalajara y Toledo. Fue entonces cuando el general Vicente Rojo, jefe del Estado Mayor republicano, decidió que era necesario retomar la iniciativa y jugarse el destino de la guerra en un todo por el todo. Expuesto el plan de actuación sobre Extremadura, el Consejo de Guerra, a instancias de Indalecio Prieto y los comunistas, desestimó la propuesta de Rojo a la vista de lo sucedido 
en Brunete y Belchite. Por el contrario, el Estado Mayor republicano decidió que la ofensiva debía realizarse sobre Teruel y no sobre Extremadura.

En principio, el rechazo oficial a la acción sobre Extremadura a favor del frente aragonés no supuso el completo abandono del "Plan P". Todavía a comienzos de 1938, después de la ocupación de Teruel por parte del ejército republicano, Rojo insistió en llevar a cabo la ofensiva sobre el eje Mérida-Badajoz. Sin embargo, la recuperación de la plaza turolense por los nacionales el 22 de febrero y la consiguiente contraofensiva franquista sobre el Ebro, que amenazaba con derrumbar todo el frente de Aragón, hicieron que la atención del Estado Mayor republicano se centrara en el teatro de operaciones aragonés. Aunque se emitió una directiva en el sentido de realizar movimientos ofensivos en torno a la zona centro, el definitivo derrumbe en abril de 1938 del frente del Ebro, con la consiguiente partición del espacio controlado por el gobierno republicano, hizo imposible cualquier intento de contraofensiva en este sentido. Paradójicamente, con la entrada de las tropas nacionales en Vinaroz, el territorio controlado por la República quedaba dividido en dos partes aisladas, esto es, los nacionales habían conseguido en el Levante el objetivo que con tanto ahínco había perseguido el Estado Mayor republicano en Extremadura.

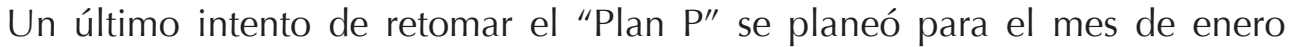
de 1939. La idea era romper el frente en el sector de Valsequillo y provocar el derrumbe del Ejército nacional en el sector Ilamado "bolsa de Mérida o de la Serena". El día 5 de enero comenzaba la ofensiva republicana bajo el mando del general Antonio Escobar, jefe del Ejército de Extremadura, y con la supervisión del general Matallana, jefe de Estado Mayor del Grupo de Ejércitos de la Región Central. Las fuerzas del Ejército Popular consiguieron en un principio romper el frente en el sector de Valsequillo y amenazaron Peñarroya y Monterrubio sin poder ocuparlas. Ha habido sospechas de que la ofensiva republicana fracasara debido a la traición o sabotaje de alguno de los mandos republicanos implicados, en concreto, a la actuación del propio Matallana, dada la defensa que éste hizo de su actuación ante los tribunales franquistas al fin de la guerra. En cualquier caso, la llegada de refuerzos nacionales y el derrumbe del frente catalán transformaron la ofensiva republicana en una nueva derrota. Una situación física y moral agravada por la caída de Barcelona en manos de Franco, que puso fin a las esperanzas republicanas de un cambio sustancial en el curso de la guerra.

\section{El final de la Guerra Civil: La "Campaña de la Victoria"}

Los planes de ruptura en el FST también salieron del Estado Mayor nacional aunque al igual que ocurrió con los republicanos, pocas veces llegaron a materializarse. Así, en agosto de 1938 se dictaron unas instrucciones reservadas que planteaban la rotura del frente al Sur de La Puebla de Montalbán, con el fin de iniciar un ataque en dirección a Ventas con Peña Aguilera que dejara 
sin sentido las defensas construidas en el entorno de Toledo y permitir con ello la penetración de las tropas nacionales hacia La Mancha. Otras instrucciones redactadas un mes después, recuperaron parte del plan y propusieron un nuevo modelo de ataque en tres puntos diferentes del FST, el mismo punto de partida en La Puebla Montalbán antes citado y dos nuevos en Toledo y Algodor.

Ambos planes constituyen un claro precedente del que se iba a diseñar el mes de marzo de 1939 que finalizó con la conocida como "Campaña de la Victoria", que es la que ahora nos interesa analizar, al constituir la última gran operación de rotura de frentes de la Guerra Civil. Su preparación implicó una preparación exhaustiva, que quedó plasmada en una interesante documentación elaborada por el Cuerpo de Voluntarios Italianos. El ejército italiano desarrolló una cartografía a detalle elaborada sobre fotografía aérea de la época que nos ha permitido contrastar nuestros trabajos documentales y de campo. Siendo coincidentes los resultados de nuestros trabajos con los suyos, lo que muestra que en Toledo contamos con un material inusual en el resto del territorio nacional.

Su inicio parece remontarse a finales del mes de enero, una vez que la caída de Barcelona no había supuesto el esperado desmoronamiento de los frentes que todavía mantenían al cuadrante sudeste peninsular bajo la obediencia republicana. La operación se planteó como una auténtica ofensiva final que sería realizada con cuatro cuerpos de ejército, los del Centro, Maestrazgo, Navarra y el Cuerpo de Tropas Voluntarias italianas del que luego nos ocuparemos, que serían los encargados de romper las defensas consolidadas desde 1937 y realizar una rápida penetración con unidades ligeras y tropas de caballería en dirección a Ocaña y Tarancón, con el fin de cortar las comunicaciones que todavía permitían la defensa de Madrid.

La organización de una campaña con tantos efectivos condicionó su punto de partida, al requerir de puentes y otras infraestructuras para cruzar el Tajo que sólo existían en Toledo y en menor medida en Talavera de la Reina, que se encontraba mucho más alejada del objetivo que se quería alcanzar. De esta manera, la población recuperó protagonismo en el escenario bélico y fue la elegida como base principal de operaciones de la poco conocida última ofensiva del Ejército Nacional, que se vería complementada por operaciones menos importantes lanzadas desde el Norte de Valencia, Andalucía y Extremadura. Para organizar esta ofensiva se realizaron toda una serie de trabajos previos en los que las tropas italianas, sus cartógrafos y observadores artilleros, tuvieron un papel destacado. A ellos les correspondió realizar el estudio del frente en Toledo para asegurar la efectividad de la artillería que debía inutilizar o disminuir la capacidad de respuesta republicana en el inicio de la operación. Fruto de este esfuerzo es la realización del amplio conjunto de planos, croquis y anotaciones, que ahora damos a conocer y que tanta información nos ofrecen sobre la situación del FST en Toledo poco antes del final de la guerra, tal y como luego podremos comprobar. 
Todos estos trabajos realizados por la "inteligencia" italiana constituyen un magnífico ejemplo de los preparativos necesarios para el comienzo de una campaña tan importante como era la que se emprendió el 26 de marzo de 1939. Su inicio vino marcado por el ataque de la artillería italiana asentada en los cigarrales, tal y como estaba previsto, que aún no era consciente de que la mayor parte del Ejército Republicano había abandonado sus posiciones. En la noche del 25 al 26 de febrero las fuerzas del Cuerpo de Ejército de Toledo, al mando del general Ponce, cruzaron el Tajo, estableciendo una cabeza de puente en la carretera de Navahermosa y llegando hasta Gálvez, sin encontrar resistencia alguna, ya que el Ejército republicano se había esfumado. Al amanecer del día 27, los tres Cuerpos de Ejército de Navarra -General Solchaga-, Maestrazgo -General García-Valiño- y C.T.V. (General Gámbara), tras un fuego artillero intenso y bombardeos aéreos, lanzaban sus divisiones a la conquista de un territorio vacío, alcanzando al finalizar el día Gálvez, Pulgar, Mazarambroz, Sonseca, Mora, Villanuelas y Yepes.El fin del Frente Sur del Tajo en el lado republicano fue dantesco debido a las deserciones en masa. Fueron escasos los oficiales que lograron mantener cierto orden en sus unidades, cuyos efectivos intentan volver a sus localidades de origen. La Guerra Civil española finalizó el 1 de abril de 1939 en el Puerto de Alicante, se formalizó con el último parte de guerra, firmado por Franco: "En el día de hoy, cautivo y desarmado el Ejército rojo, han alcanzado las tropas nacionales sus últimos objetivos militares. La guerra ha terminado. Burgos, 1 de abril de 1939. Año de la Victoria". El parte se llevó a la sede de Radio Nacional de España en Burgos en el Paseo del Espolón, donde el actor Fernando Fernández de Córdoba, locutor habitual, lo transmitió a todo el país.

Por último, queremos acabar haciendo una Ilamada por la conservación de este paisaje de la guerra, que es sumamente frágil y se ve amenazado por las continuas trasformaciones en el paisaje ${ }^{6}$, así como por el expolio continuado de su materiales muebles, sin cuya presencia no habríamos podido realizar este estudio.

\section{Bibliografía}

R. BARROSO CABRERA. et al. (2011): "Arqueología de la Guerra Civil en Toledo. El Frente Sur del Tajo y el Cigarral de Menores: un escenario de guerra", Archivo Secreto. Revista Cultural de Toledo, 5, pp. 330-348.

R. BARROSO CABRERA et al. (2014): La Guerra Civil en Toledo: El Frente Sur del Tajo. Metodología para el estudio de un frente de la guerra civil española, en VII Jornadas del Patrimonio Arqueológico de la Comunidad de Madrid (Madrid, 2010). Madrid, 2014, pp.

6 Los trabajos realizados han sido recogido en una monografía: J. CARROBLES SANTOS y J. MORÍN DE PABLOS, J. -eds.- (2015). Arqueología de la guerra civil española. Propuesta metodológica para el estudio de los paisajes de la guerra. 1936-39 Toledo. Madrid. 
J. CARROBLES SANTOS y J. MORÍN DE PABLOS -eds.- (2014): Los paisajes culturales de la ciudad de Toledo. Dehesas, espacios irrigados, torres, cigarrales y trincheras. BAR Internacional Series 2638. Oxford, 2014.

J. CARROBLES SANTOS y J. MORÍN DE PABLOS, J. (2015). Arqueología de la guerra civil española. Propuesta metodológica para el estudio de los paisajes de la guerra. 1936-39 Toledo. Madrid.

J. CARROBLES SANTOS y J. MORÍN DE PABLOS -eds.- (2015): Torres, cigarrales y trincheras. El Cigarral de Menores. Toledo.

L.A. RUIZ CASERO (2014): Los combates al Sur del Tajo: Un enfoque patrimonial de un escenario de la Guerra Civil. Madrid.

L.A.RUIZ CASERO (2015): Más allá del Alcázar. La batalla del sur del Tajo. Toledo y Argés. Madrid. 